\title{
Exploration and Practice on Training Mode of Innovative Network Engineering Talents
}

\author{
Leian Liu and Ying Zou
}

\begin{abstract}
This paper analyzes the current situation of innovative talent cultivation and summarizes the main factors that restrict the cultivation of innovative network engineering talents. Combined with the actual situation of our university, the "six-in-one" innovative network engineering talent training system is proposed. The practical results show that the training system is effective.
\end{abstract}

Index Terms-Innovation, network engineering, training mode.

\section{INTRODUCTION}

With the rapid development of economic construction and science and technology, and also with the improvement of international level, the country needs more and more high-level and high-quality innovative talents. Since the 1990s, the cultivation of innovative talents has become a hot issue in the discussion of higher education and teaching reform in various countries around the world. China's successive central governments have also attached great importance to the issue of training innovative talents in China As early as 2003, former president $\mathrm{Hu}$ Jintao emphasized in the National Talent Work Conference that the issue of talent is a key issue in the development of the party and the country. The comrades of the whole party must take the implementation of this strategy as an important and urgent task of the party and country at present with a high sense of political responsibility and historical mission, and strive to create hundreds of millions of high-quality laborers, tens of millions of specialized talents and a large number of top-notch innovative talents. Since 2006, the government has further vigorously advocated innovative education, and the Ministry of Education has begun to plan and implement the "National College Student Innovation Experiment Program". In 2010, "the Outline of the National Medium- and

Manuscript received October 31, 2018; revised April 12, 2019. This work was financially supported by the quality resource sharing course project-"Computer Network" (Official document by Department of education of Guangdong province ([2015] no. 133)), the provincial-level characteristic specialty-"Network Engineering" and the provincial teaching team-"Teaching team of basic core course of computer major" (Official document by Department of education of Guangdong province ([2017]214)), 2018 higher education teaching reform project of Guangdong province-"Reform and practice of the training mode of network engineering talents based on the cooperation of school-school and school-enterprise", the university-level high-quality resource sharing course project-"Network Security Technology" and "Wireless Sensor Network and RFID Technology", and the Science and Technology Planning Project of Guangdong Province under Grant (2017A070709012).

The authors are with the College of Information Science and Technology of Zhongkai University of Agriculture and Engineering, China (e-mail: 1la@zhku.edu.cn, blueleaf@126.com).
Long-Term Science and Technology Development Plan" puts the outstanding training of innovative scientific and technological talents and engineers in the first place. In 2012, the report of the 18th National Congress of the Communist Party of China clearly identified the "Improvement of the level of innovative talents training" as an important goal for building a well-off society in an all-round way. In 2015, the Central Committee of the Communist Party of China promulgated documents-"Several Opinions of the Central Committee of the Communist Party of China on Deepening the Reform of System and Mechanism and Accelerating the Implementation of Innovation-Driven Development Strategy", with particular emphasis on building a more efficient research system and innovation culture, and attracting talents with a good mechanism to promote the formation of deep integration of open innovation situation are emphasized particularly. In February 2017, the Ministry of Education, the Ministry of Finance and the National Development and Reform Commission promulgated the "Implementation Measures for the Overall Promotion of the Construction of World-class Universities and First-class Disciplines (provisional)" (Teaching and Research [2017] No. 2). It clearly put forward the implementation of the "Double First-rate" training plan for innovative talents, focusing on the cultivation of innovative spirit and practical ability of all kinds of top-notch innovative talents and technical talents badly needed by the economy and society. General Secretary Xi Jinping pointed out at the academician meeting of both academies held on May 28, 2018 that "Full understanding of innovation is the first driving force" and "Youth is the future of the motherland, the hope of the nation, and the future of innovation". Since 2006, many scholars in China have also conducted a lot of research on innovative talents and published relevant academic papers. For example, "Reform Practice Teaching Model, Cultivate Innovative Engineering Talents" [1], by Li Yuanyuan, the former president of South China University of Technology; "Ten Elements of the Cultivation of Innovative Talents" [2], by Wang Shuguo, the former president of Harbin Institute of Technology; "Promote Innovative Practices, Cultivate Innovative Talents" [3], by Li Yinguo, the former president of Chongqing University of Posts and Telecommunications; "Explore New Mechanisms for Top Creative Talents Cultivation" [4], by Du Yubo, the former deputy minister of education of China, and so on.

At present, higher education has gradually entered the stage of popularization. The diversity and application of higher education are more and more prominent. How to grasp the opportunities and meet the challenges, focus on the undergraduate application-oriented orientation, survive by 
quality, develop with characteristics, and cultivate innovative talents are the core issues that local undergraduate universities and colleges must solve in education and teaching practice. Most of the local undergraduate universities and colleges in China have established network engineering specialty, and their undergraduate graduates have played an important role in the construction of network informatization. However, restricted by many factors, such as the level of students, the structure and level of teachers, these graduates have no advantages in the increasingly competitive society and lack employment competitiveness, which is quite far from the requirements of the society. The cultivation of network engineering talents in local undergraduate universities and colleges should start from reality and focus on cultivating innovative engineering talents who serve the needs of economic and social development.

\section{RESEARCH StATUS OF INNOVATIVE NETWORK ENGINEERING TALENTS TRAINING}

At present, China is in an important transitional stage of comprehensively deepening reforms and accelerating the transformation of economic development mode. How to cultivate innovative talents has become the key to the driving force of China's future development. The cultivation of innovative network engineering talents has also attracted the attention of scholars. Literature [5]-[9] studied the training mode of innovative talents in network engineering; the literature [10], [11] discussed the cultivation of innovative network engineering talents from the practical teaching system; the Literature [12]-[14], from the perspective of discipline competition, discussed the promotion effect of discipline competition on innovative network engineering talents training; the literature [15], [16] discussed the effect of the integration of science and education on the cultivation of innovative talents; the literature [17] discussed the effect on the cultivation of students' innovation ability from the aspect of course examination reform.

\section{MAin FACtORS Restricting the CUltivation OF INNOVATIVE NETWORK ENGINEERING TALENTS}

At present, the following problems exist in the training of network engineering talents. These problems become the main factors that restrict the training of innovative network engineering talents.

\section{A. Outdated Theoretical Knowledge System and Insufficient Innovation Content}

With the rapid development of information technology, the mutual integration and penetration of technology is more and more common. The goal of cultivating talents for network engineering should be changed with the development and progress of the times, and its knowledge system should be updated with the development of information technology. At present, due to the development and integration of technologies such as Internet of things technology, big data technology, mobile Internet, cloud computing, artificial intelligence and other technologies, new requirements and challenges have been put forward for the cultivation of network engineering talents. However, through the investigation and research of the current talents training program of network engineering, it is found that many colleges and universities have not updated the knowledge system and new network-related technologies are not added into the talent training program. In addition, knowledge related to innovation and entrepreneurship is insufficient, and there is no content of innovation and entrepreneurship or incomplete content of innovation and entrepreneurship in the talent training program. In short, the entire theoretical knowledge system lacks frontier and innovative knowledge, which is not conducive to the cultivation of innovative network engineering talents.

\section{B. Faculty Team Focuses on Theoretical Research, Lacking Engineering Practice Ability and Innovation Ability}

Teachers play an important role in educational innovation, and innovative teachers play a key role in the cultivation of innovative talents. At present, the source of university teachers is mainly high-educated talents. They basically work as teachers directly after graduating from colleges and universities. At present, professional title evaluation in China mainly focuses on scientific research results. Therefore, teachers mainly focus on scientific research, application of scientific and technological projects and academic paper publication. They do not invested enough energy in teaching, and are even less willing to participate in enterprise engineering practice projects to improve their engineering practice ability. Although these teachers have made some achievements in scientific research, their engineering practice ability is relatively weak due to the lack of enterprise project experience. Finally, more attention is paid to the teaching of theoretical knowledge in the teaching process, which is difficult to effectively cultivate students' scientific practice and engineering technology innovation ability, thus resulting in that students' engineering practice ability cannot be improved. For application-oriented universities and colleges, this is a serious flaw. The more prominent problem is that the teachers participating in innovation education do not have the ability of innovation themselves, with outstanding professional ability only in a certain aspect, seriously affecting the cultivation of students' innovation ability. In addition, in the current environment of innovation and entrepreneurship, many colleges and universities have innovative talent training programs and established the innovation and entrepreneurship department. But at present, there are almost no innovative teacher training programs. The common practice of colleges and universities is to select some innovative teachers as the innovation instructors, or recruit some technical elites from enterprises as the supplement of innovative teachers. However, it is still unknown how effective the training of innovative talents can be. Weak innovation consciousness, weak innovation ability and weak scientific research ability all affect the formation of innovative education teachers [18].

\section{Single Teaching Method, Low Student Participation}

The teaching method has significant influence on the teaching effect. The teaching method adopted in most courses in colleges and universities is single and the teaching 
effect is very poor. At present, the following problems generally exist in the course teaching of network engineering.

- Traditional teaching mode is often adopted. In the classroom, teachers focus on teaching professional knowledge. The classroom is dominated by "teacher-speaking and student-listening", and students lack the training of innovative thinking methods.

- Classroom teaching only focuses on the knowledge of the single course itself, and there is little guidance on the frontier knowledge related to the course.

- Students' initiative to participate in the course learning is insufficient, and the course assessment method is single.

- Some students have a good grasp of theoretical knowledge in class, but their ability of knowledge development and innovation is insufficient.

\section{Unreasonable Practice Link, and High-Level} Innovation Practice Platform Lacking

The problems existing in the practical teaching of network engineering are as follows: the practical teaching system is not systematic; the innovative experiments are insufficient; the high-level innovative practice platform is lacking; the practical teaching is out of line with employment. Professor Zuo Tieyong, an academician of the Chinese Academy of Engineering, said: "The laboratory is half of the university" [19]. However, due to the rapid update of network technology and the relatively expensive equipment of network laboratory, it is difficult for colleges and universities to update the equipment in time, which puts forward a new problem and challenge for the cultivation of students' practical ability. At present, there are many problems in university network laboratory, such as outdated equipment, isolated network equipment, inadequate resources, and so on. Owing to the outdated equipment of network laboratory and the lack of high-level innovation practice platform, it is a big obstacle to cultivate innovative network engineering talents.

\section{E. Unbalanced Development of Teaching and Scientific Research}

Scientific research and teaching are the two basic functions of colleges and universities. The integration of scientific research and teaching is the inherent logic requirement of the essence of higher education [20]. The cultivation of innovative talents needs to be supported by advanced, up-to-date and cutting-edge teaching contents. At present, however, many colleges and universities teaching contents are outdated and do not match the current scientific and technological progress. The latest scientific research results are integrated into the teaching, and the knowledge taught can hardly meet the needs of frontier scientific research. Students are seriously short of frontier knowledge of the subject. They can only get a little scratch from the Internet. The development of scientific research and teaching is seriously unbalanced, which leads to the serious lack of talent innovation and entrepreneurship ability. Therefore, to solve the problem of unbalanced development of scientific research and teaching, and realize the integration of science and education is a major problem that must be faced directly by China's higher education circles at present. Colleges and universities should coordinate the relationship between teaching and scientific research, carry out the integration of science and education, so as to cultivate innovative talents needed by the country and the society [21].

\section{F. Insufficient Innovation Culture Construction}

The construction of innovation culture is very important to the cultivation of students' innovation ability. The influence of environment on a person is subtle. Although all colleges and universities have attached great importance to the cultivation of students' innovative ability, there are some shortcomings in the construction of innovative culture. This is mainly reflected in the absence of an innovative atmosphere on the whole. Various innovative activities are temporary, isolated and unsystematic. Therefore, it is difficult to fundamentally solve the problem of cultivating students' innovative ability.

\section{TRAINING PRACTICE OF INNOVATIVE NETWORK ENGINEERING TALENTS}

On the basis of investigating the work of predecessors in the cultivation of innovative talents, aiming at the main factors restricting the cultivation of innovative network engineering talents in the third part and combining with the actual situation of our university, the "six-in-one" innovative network engineering talents cultivation system is proposed, as shown in Fig. 1.

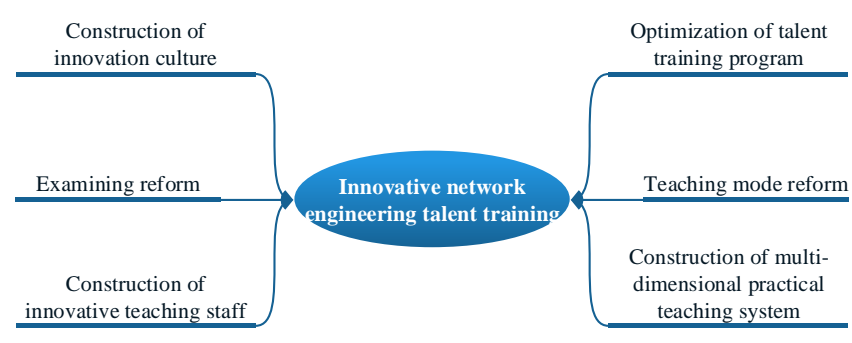

Fig. 1. "Six-in-one" innovative network engineering talents cultivation system.

\section{A. Revising the Talent Training Program in Time}

The talent training program is a programmatic document for cultivating students. The network engineering specialty of our university has optimized the talent training program with the focus on innovation ability and engineering ability. The talent training program combines the guiding ideology and characteristics of our university-"focusing on practice and supporting agricultural workers". Led by the reform of innovation and entrepreneurship education, the talent training program closely relies on the professional education to carry out diversified talent training. It aims to train high-quality applied talents with potential for innovation and entrepreneurship for the innovation-driven and economic and social development in our province. The talent training program has formed an innovative and entrepreneurial education system that covers the whole process of teaching and integrates into various teaching links, and comprehensively enhances students' innovative thinking and spirit, entrepreneurial awareness and potential. In the freshman and sophomore stages, innovative and 
entrepreneurial general education courses such as discipline frontiers, entrepreneurial foundation and entrepreneurial guidance are set up to cultivate students' overall awareness of innovation and entrepreneurship. In the junior and senior professional courses, we integrate innovation and entrepreneurship thinking into classroom teaching, classroom discussion, curriculum design and other teaching links in order to cultivate critical and creative thinking of the students and inspire their innovation and entrepreneurship inspiration and potential. At the same time, combined with the development of information technology, new technologies are added into the theoretical teaching and practical teaching, so that students can master the frontier knowledge of the discipline and put it into practice. In the newly revised talent training program for network engineering, the total credits of innovation and entrepreneurship education reached more than 12 credits.

\section{B. Construction of Innovative Teaching Staff}

Teachers are the soul of a university, and the construction of the teaching staff is the core of innovative talent training. The cultivation of innovative talent ultimately depends on the first-line teachers, so the construction of teaching staff should be in the core position. Young teachers account for a large proportion of the teaching staff, especially for IT disciplines, and they are also the main basis for training top-notch innovative talents. In order to better cultivate young teachers, teachers of network engineering have established corresponding teaching teams according to the different course groups established. Team teachers learn from each other, promote each other and improve together. At present, the computer foundation teaching team is approved as a provincial teaching team in 2017 and the network technology core courses teaching team is approved as a university-level teaching team in 2016.

In order to improve the theoretical knowledge level of teachers, they are encouraged to visit famous universities at home and abroad. Up to now, three young teachers have been sent to the United States, Australia and Singapore for visiting studies and five young teachers have been sent to Sun Yat-sen University, South China University of Technology and Jinan University for visiting studies in China. In addition, in order to enhance teachers' engineering practice ability, they are sent to work and study in IT enterprises during the two vacations each year. More importantly, we attach great importance to the cultivation of teachers' innovation ability and select teachers to participate in innovation and entrepreneurship-related training. In recent years, network engineering teachers have obtained HCNA certificate, HCNA certified instructor certificate, HCNP certificate, "National Software Professionals" certificate, "Advanced Software Development Engineer" certificate, "IoT Development Senior Engineer" certificate, "Information Security Engineer" certificate, etc. Teachers' engineering practice ability has been strengthened and the teaching effect has been further improved. In addition, one teacher obtained the "Innovation and Entrepreneurship Instructor Certificate" issued by the School-Enterprise Cooperation Committee of the University Graduates Employment Association of the Ministry of Education. In short, through the above mentioned ways, an innovative team of teachers has been constructed.

\section{Curriculum Resources Construction and Reform of Teaching and Assessment Methods}

Combined with the talent training program, the theoretical course system of network engineering specialty is optimized, and several large course groups are established. According to the research direction of each teacher, 2-3 teachers in each curriculum group are responsible for the construction. The annual tasks and objectives of the course construction are given, and the summary and assessment are carried out at the end of the year. With outstanding emphasis, clear tasks and annual progress, the curriculum resources construction has been advanced to a new level in 2-3 years, laying a solid theoretical foundation for the cultivation of innovative network engineering talents.

At present, network engineering teachers have compiled several textbooks as the chief editor or associate editor, such as "Network Security Technology", "Network and Information Security", "Network Security Principle and Application", "Computer Networks", and so on. A whole set of network technology core course textbook resources is forming gradually. In addition, network engineering teachers take the initiative to strengthen the development of online course resources and continuously enrich the teaching resources of network courses. Until now, they have developed teaching websites of "Computer Networks", "Network Security Technology" and "Routing and Switching Technology", which provide great convenience for students and colleagues. Through continuous construction, the course of "Computer Networks" was approved as the high-quality resource sharing course project of Guangdong Province in 2015, and "Network Security Technology", "Wireless Sensor Network and RFID Technology" were approved as the university-level high-quality resource sharing course project in 2016 and 2017 respectively. The construction of online course teaching resources provides support for the reform of teachers' teaching methods. Through the online course platform, teaching methods such as "flipped classroom", "case teaching method" and "group discussion method" can be implemented better, so that students can truly become the subject of learning, and the interaction between teachers and students can be promoted to the maximum extent, thus enhancing students' learning enthusiasm. In the computer education software evaluation activities of Guangdong Province in 2018, the "Computer Networks" course won the second prize of the Higher Education Group Information Teaching Course.

At present, examination is still the baton of students' learning. The contents, forms and evaluation methods of examination have a strong guiding effect on students' learning choices, which not only directly affects students' learning methods, learning ability and thinking ability, but also ultimately affects the development and direction of the university's talent cultivation goals [22]. However, due to the lack of online course resources, the curriculum examinations of most universities in China do not deviate from the track of "exam-oriented education", which has become the bottleneck of cultivating high-quality innovative talents [23]. Through 
the online course platform, students' performance can be fully assessed. It is no longer limited to the final exam results and can track and evaluate the whole process of students' learning. The student's course grade consists of six sections such as class attendance and participation performance $(5 \%)$, group discussion $(5 \%)$, coursework $(10 \%)$, experimental operation and report $(15 \%)$, online course platform learning (15\%) and final examination (50\%), as shown in Fig. 2. According to the characteristics of different courses, the performance evaluation composition is slightly different.

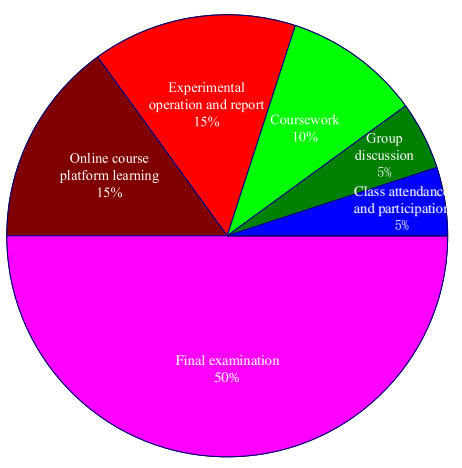

Fig. 2. Pie chart of course grade.

\section{Construction of Multi-dimensional Practical Teaching System}

A relatively perfect practical teaching system has been established, including the course experiment teaching system, the course design and practice teaching system, and the innovation ability practice teaching system. These three aspects are progressively and gradually improved. The course experiment is the foundation, mainly is the comprehensive experiment and the design experiment. Course design and practice are to improve and strengthen the ability to comprehensively use two or more courses. The practical teaching system of innovation ability is expanded and emphasizes the cultivation of students' innovation ability. In order to improve students' practical ability, we opened the agricultural IoT Virtual Simulation Experiment Teaching Center, which was approved by the provincial virtual simulation experiment teaching center of Guangdong Province in 2016. The center's online learning platform has experimental resources for multiple courses and an innovative experimental platform. Students can log on to the center's online learning platform remotely and conduct online experiments. In addition, through school-enterprise collaboration, we have built a high-level innovation practice platform with a number of IT companies. In particular, in 2015, we and Huawei technologies co., ltd. signed the "Huawei Information and Network Technology Institute" cooperation agreement, providing a good platform for students to carry out network technology innovation practice.

\section{E. Good Innovation Atmosphere Construction}

The innovative culture can provide abundant soil for the cultivation of innovative talents, and is a solid carrier for talents to go to the other side of innovation and entrepreneurship. Insisting on cultural education, creating innovative cultural atmosphere, and enabling students to develop innovative cultural literacy and scientific thinking are also important parts of cultivating innovative talents [24]. Our institute has done some work in the aspect of the construction of innovative culture, and constructed a good innovative atmosphere, trying to make the innovative consciousness deep into students' heart. The main practices are as follows:

- Scientific research experts, industry experts and innovation and entrepreneurship tutors are invited to give lectures to students on frontier knowledge of the subject, cutting-edge technology of the industry and innovation and entrepreneurship knowledge from time to time.

- Regular IT culture festival. We hold IT culture festival every year, which lasts for about one and a half months. Based on IT culture festival, the project of competition is set up, and students are selected to participate in provincial and national competitions.

- Regular college students' innovation and entrepreneurship fund project guidance and application. Teachers' guidance team are set up to guide students to apply for the project of University Students' Innovation and Entrepreneurship Fund, guide students to select topics and write project declaration, and give specific guidance to students in the process of project development. After the project is completed, students are instructed to summarize the results and write academic papers, apply for software copyrights or patents, etc.

In addition, teachers have made some achievements in the mutual promotion of scientific research and teaching. For example, teachers' research results are integrated into the edited textbooks; In the process of classroom teaching, the frontier knowledge of the subject is imparted to the students; In the experimental teaching, teachers developed the hardware and software products by relying on their own research projects and set up innovative experimental projects; Through the online course platform, teachers combine some knowledge points with their scientific research results, and so on.

\section{CONCLUSION}

Through continuous exploration and practice in recent years, the innovation atmosphere of network engineering specialty is gradually formed. The innovation ability and consciousness of students are strengthened and the engineering practice ability of teachers is improved. In the past three years, students have won 23 provincial or above awards related to network technology. In particular, in 2017, a student won the first prize of the 2016-2017 College ICT Skills Competition of Huawei Information and Network Technology. Students participate in the declaration of 20 software copyrights and patents. "Innovation and practice of information innovative talents training mode coordinated by the school and enterprise" won the second prize of the eighth education teaching achievement award of our university in 2016. "Construction and implementation of the applied innovative talent training mode with team building as the focal point" and "Experimental teaching and innovative practice platform of Internet of things" won the second prize of the ninth education teaching achievement award of our 
university in 2017. In 2017, the network engineering specialty was approved as the "Characteristic Specialty" construction project in Guangdong Province.

The cultivation of students' innovative ability is a systematic project. Different colleges and universities have different approaches according to their own characteristics. The training of innovative network engineering talents in our university has achieved some achievements, but it still needs to be summarized and further improved.

\section{ACKNOWLEDGMENT}

I would like to take this opportunity to thank my colleague, Ying Zou, for giving me a lot of help in the process of finishing this paper. She has also contributed to many of the achievements mentioned in the paper.

\section{REFERENCES}

[1] Y. Y. Li, Z. Li, and X. M. Xu, "Reform practical teaching mode to cultivate innovative engineering talents," China Higher Education, no. 23, pp. 31-32, December 2006.

[2] S. G. Wang, "Ten elements for cultivating innovative talents," China Higher Education, no. 23, pp. 20-22, December 2006.

[3] Y. G. Li, D. Zhang, and C. Y. Yuan, "Promote innovative practices and cultivate innovative talents," China Higher Education, no. 8, pp. 43-46, April 2014.

[4] Y. B. Du, "Explore new mechanisms for cultivating innovative talent," China Higher Education, no. 2, pp. 4-6, January 2014.

[5] Q. Huang, D. Q. Xiao, Z. G. Du, and J. J. Yin, "Thoughts and practices on training network engineering innovation talents," Research and Exploration in Laboratory, vol. 36, no. 9, pp. 193-195, September 2017.

[6] B. Liu and F. Shen, "The training ideas of innovative and applied talents for network engineering major," Agriculture Network Information, no. 248, pp. 83-86, February 2017.

[7] Z. Wang, "Reform and innovation of the training mode of network engineering talents in application-oriented universities," Journal of Mudanjiang University, vol. 26, no. 6, pp. 175-178, June 2017.

[8] Y. J. Zhang, J. S. Wu, D. Yang, and L. X. Sun, "Innovation and entrepreneurship education research and reform practice in network engineering," The Guide of Science \& Education, no. 9, pp. 29-30, March 2018.

[9] X. J. Kong, Z. Yang, Z. L. Ning, H. Hui, and F. Xia, "Explore the training system of top-notch innovative talents for network engineering specialty oriented to 'Internet +'," Computer Education, no. 9, pp. 30-34, September 2018.

[10] J. Feng, H. P. Tian, J. Zhao, H. M. Jin, and X. Y. Luo, "Innovation-oriented network engineering practice teaching system construction," Journal of Higher Education, no. 17, pp. 34-35, June 2017.

[11] C. J. Guo, Z. M. Li, and Y. J. Shen, "Research on network engineering professional practice teaching reform and innovation in application-oriented undergraduate universities," Computer Knowledge and Technology, vol. 14, no. 17, pp. 205-206, June 2018

[12] L. Li, J. B. Li, Z. G. Zhao, and Q. Li, "Research on innovative network talent cultivation model driven by competition," Contemporary
Education Research and Teaching Practice, no. 9, pp. 97-98, 101, September 2018

[13] D. Y. Li, W. M. Hu, Y. Liu, W. F. Chen, J. J. Xi, and D. J. Li, “Thinking and practice of the cultivation of new engineering innovative talents relying on subject contest," Guangdong Chemical Industry, vol. 45, no. 2, pp. 221-222, January 2018.

[14] X. Li, "Research on the role of college students' discipline competition in cultivating innovative talents in the new era," Education Modernization, no. 21, pp. 1-2, May 2018.

[15] R. M. Wang, X. H. Chen, H. Niu, and Y. M. Fan, "Innovative talent cultivation under the integration of science and education," China Higher Education, no.10, pp. 49-51, May 2018.

[16] Y. R. Liu, J. Zhang, T. Han, L. Li, J. B. Wang, and T. J. Zhang, "Training innovative talents based on collaborative innovation and integration of science and education," Journal of Higher Education, no. 6, pp. 35-37, March 2018.

[17] Y. W. Hu and Y. Q. Gao, "Study on the reform of course examination under the guidance of cultivating students' innovative ability," Journal of Innovation and Enterprise Education, vol. 7, no. 5, pp. 134-136, October 2016.

[18] M. Liu, "The mission, problems and countermeasures of cultivating innovative talents in normal universities," China University Teaching, no. 8, pp. 16-19, August 2008.

[19] S. T. Xu and L. F. Zeng, "Strengthening experimental team construction and promoting the creative talents cultivation," Research and Exploration in Laboratory, vol. 28, no. 9, pp. 152-154, September 2009.

[20] H. B. Chen, "On unity of researching and teaching and cultivation of application-oriented innovative talents," Research in Higher Education of Engineering, no. 4, pp. 141-145, August 2017.

[21] J. L. Yao, "The integration of science and education improves the quality of higher education," China Higher Education, no. 5, pp. 44-45, March 2012

[22] P. Wang, "An analysis of strengthening examination management in colleges and universities," Forum on Contemporary Education, no. 10 , pp. 92-93, October 2011

[23] Z. J. Ye, "Exploration of improving the management level of curriculum examination in colleges and universities," Forum on Contemporary Education, no. 1, pp. 22-23, January 2011.

[24] Y. L. Du and H. G. Ping, "Research on the cultivation of innovative talents from the perspective of discipline culture," Education Exploration, no. 2, pp. 77-80, April 2017

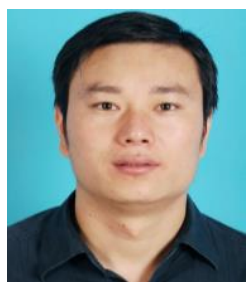

Leian Liu is an associate professor in computer science and technology, Zhongkai University of Agriculture and Engineering, China. He received the $\mathrm{Ph} . \mathrm{D}$. in circuits and systems from South China University of Technology. He is a member of Guangdong Institute of Electronics and China Computer Federation. Currently, he is interested in the research areas such as IoT technology, network security, and embedded technology, etc.

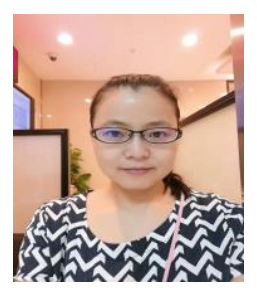

Ying Zou was born in Henan, china in 1979. She is currently a lecturer in Zhongkai University of Agriculture and Engineering, China. She is a member of China Computer Federation. Her research interests include: network security technology, IoT technology and machine learning. In recent five years, as the first author has published 1 paper, chaired three software copyright. 